\title{
COMPLETE HEART BLOCK IN CHILDREN REPORT OF THREe CASES POSSIBLy ATTRIBUTABLE TO MEASLES
}

\author{
BY \\ NORMAN S. CLARK, B.Sc., M.B., Ch.B., M.R.C.P., D.C.H. \\ (From the Royal Aberdeen Hospital for Sick Children)
}

Heart block, congenital or acquired, is an uncommon condition in childhood; as a sequel to measles it is extremely rare. The three cases here reported are, therefore, of some interest, as in all three there is evidence of complete heart block having developed either during or shortly after an attack of measles. Furthermore, although Case 1 has since died, all three survived the immediate effects of the development of heart block.

White (1945) mentions congenital lesions, syphilis, diphtheria, rheumatism, bacterial endocarditis, and, very rarely, neoplasms, miliary tuberculosis, and trauma as causes of auriculo-ventricular block in the young. Seham (1925) in a review in Abt's 'Pediatrics, summarizes thirty-two cases of heart block in children reported up to that date. Of these cases, ten were associated with congenital lesions, nine with diphtheria, and the remainder with a variety of conditions, among them one definitely and one doubtfully associated with measles, and one with measles and influenza. Bower (1939) describes two cases in adolescents, which he attributes to measles, but the association cannot be regarded as proved, for the attack of measles had occurred in one case ten years and in the other fourteen years before the heart block was discovered; in one case there had also been a severe attack of influenza in the interval; furthermore there is no evidence that these cases were not congenital in origin. Logue and Hanson (1945) report a case of transient complete heart block in an American soldier during an attack of German measles which ran such an atypical course that the diagnosis must be regarded as doubtful. According to Leys (1943), " partial and transient heart block is, of course, common enough in the acute infections, but, if it should become complete, the patient usually dies.' This is certainly true of diphtheria, the acute infection most commonly associated with heart block, for all reports agree that survival for any length of time after the development of complete heart block is unusual.

\section{Case Reports}

Case 1. A boy, aged two years, was admitted to this hospital on Feb. 2, 1946, for the investigation of ' fits.' The first fit had occurred on Feb. 23, 1945, during an attack of measles; in the next two weeks he had about forty fits, and on March 7, 1945, he was admitted to Aberdeen City Hospital for Infectious Diseases, where physical examination showed no abnormality other than signs of bronchitis and a mild catarrhal otitis media. During his stay in hospital at this time no fits occurred; he remained afebrile and his pulse rate varied between 80 and 112 . His cerebrospinal fluid was normal. On account of the pulmonary signs he was given a course of sulphadiazine. After his discharge from hospital on March 26, 1945, the fits recurred and continued at intervals; as a rule he had one to eight fits every day for a period of a week or two; then followed an interval, usually of about three weeks, during which he had no fits, and thereafter the cycle began again. The parents gave the following description of the fits: "Sometimes there is no warning. sometimes he is fretful for a few minutes; he then gives a cry and falls down; he stops breathing and becomes blue and stiff; he remains like that for about two minutes, during which breathing starts slowly; he then becomes pale and passes off to sleep.' No clonic movements had ever been noticed but incontinence was common.

FAMILY HISTORY. The parents are alive and healthy; the patient was the fourth of five children, all healthy.

Previous history. His birth was precipitate but otherwise normal. He had always been subject to colds, but apart from the attack of measles had had no other illnesses.

Physical examination. He was a well-developed, bright, but very nervous child. There was no cyanosis nor dyspnoea. There was muco-pus in the nasopharynx. The pulse was regular and of good volume, and its rate was 24 per minute. The apex beat was not palpable; the heart sounds were regular and pure, 24 per minute, with frequent feeble sounds audible during diastole-probably auricular beats. There was a systolic murmur at the left sternal border, loudest in the third space, conducted to the pulmonic area and for a short distance towards the apex. The blood pressure was $125 / 20 \mathrm{~mm}$. Hg. There were rhonchi at all areas of the lungs. The liver edge was one finger's breadth below the costal margin. No other abnormality was detected.

INVESTIGATIONS. A radiograph of the chest 


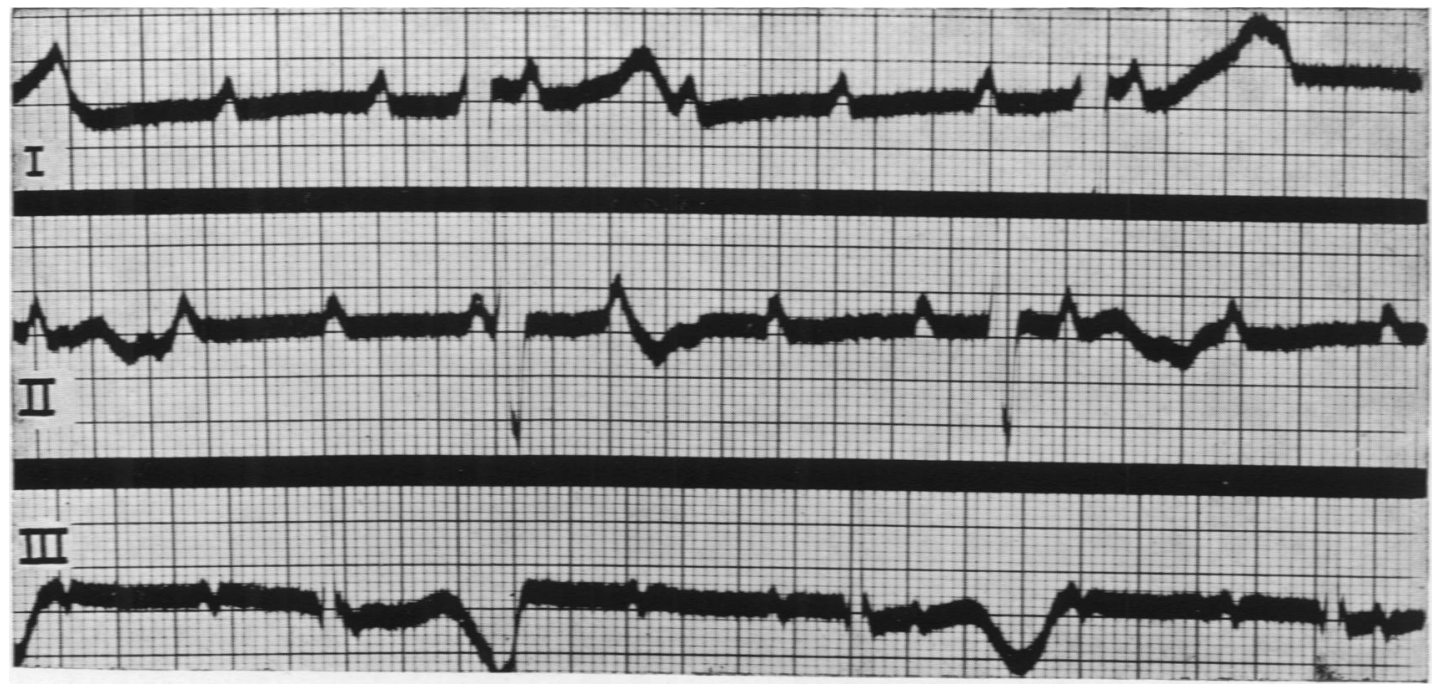

Fig. 1.-Case 1: electrocardiogram on Feb. 3, 1946.

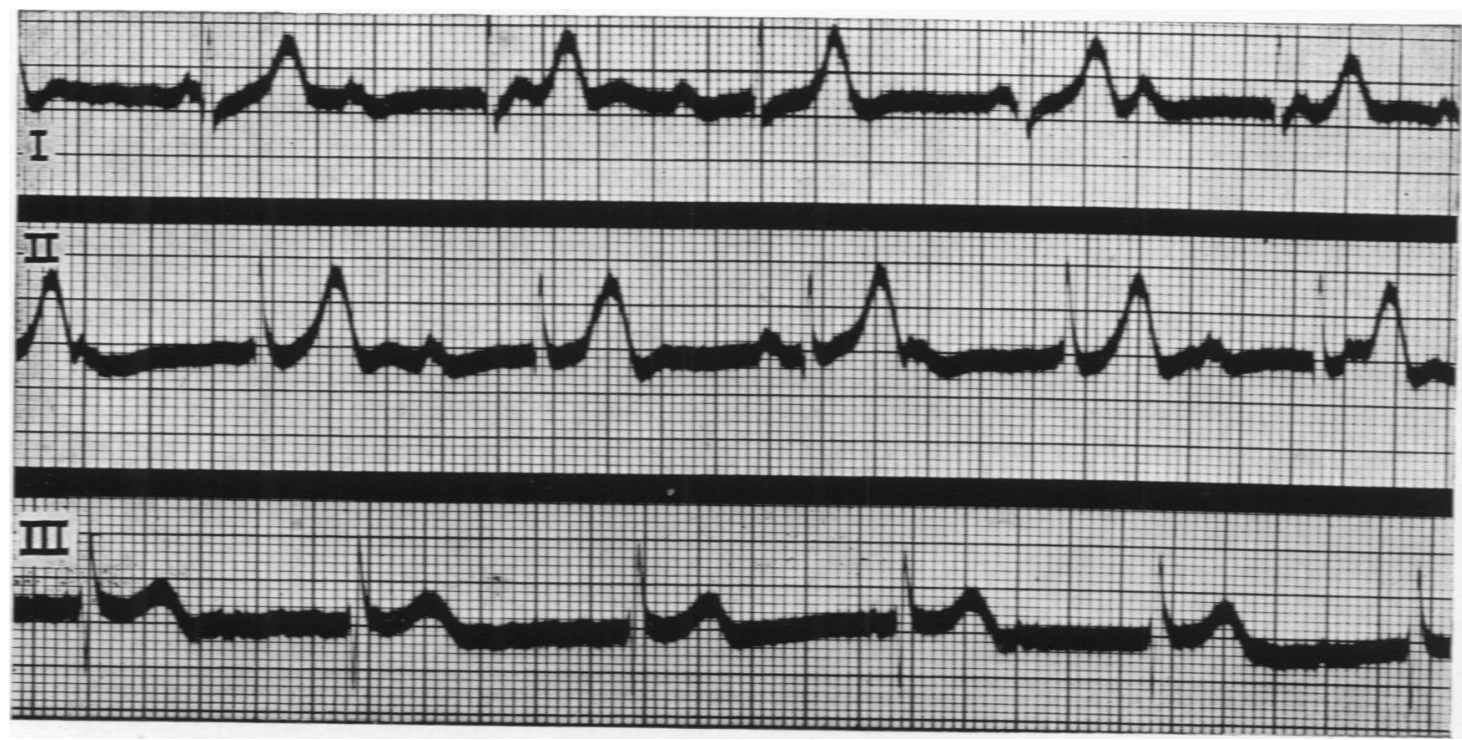

Fig. 2.-Case 2: electrocardiogram on March 7, 1947. 


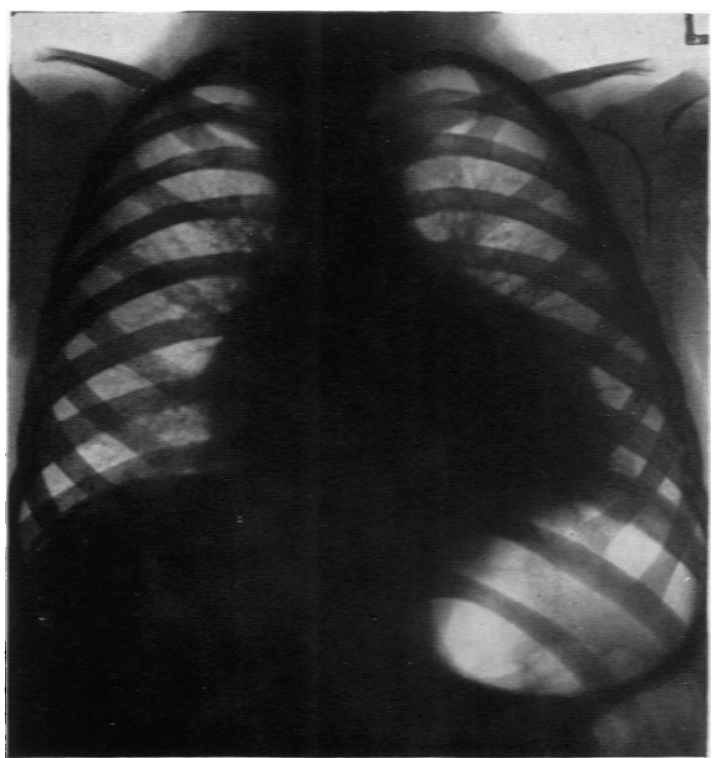

Fig. 3.- Case 2: radiograph of chest on March 10, 1947.

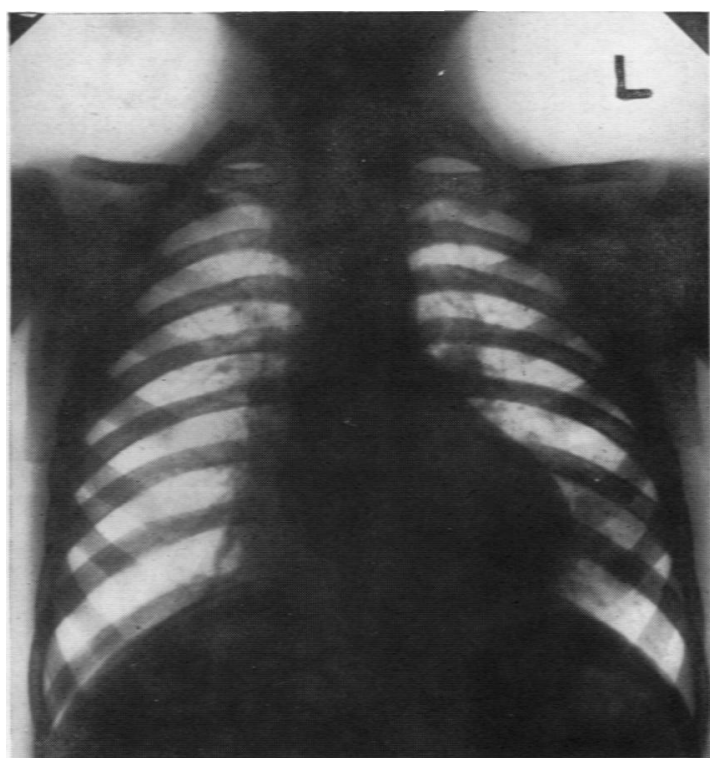

Fig. 4.-Case 3: radiograph of chest on March 20, 1947.
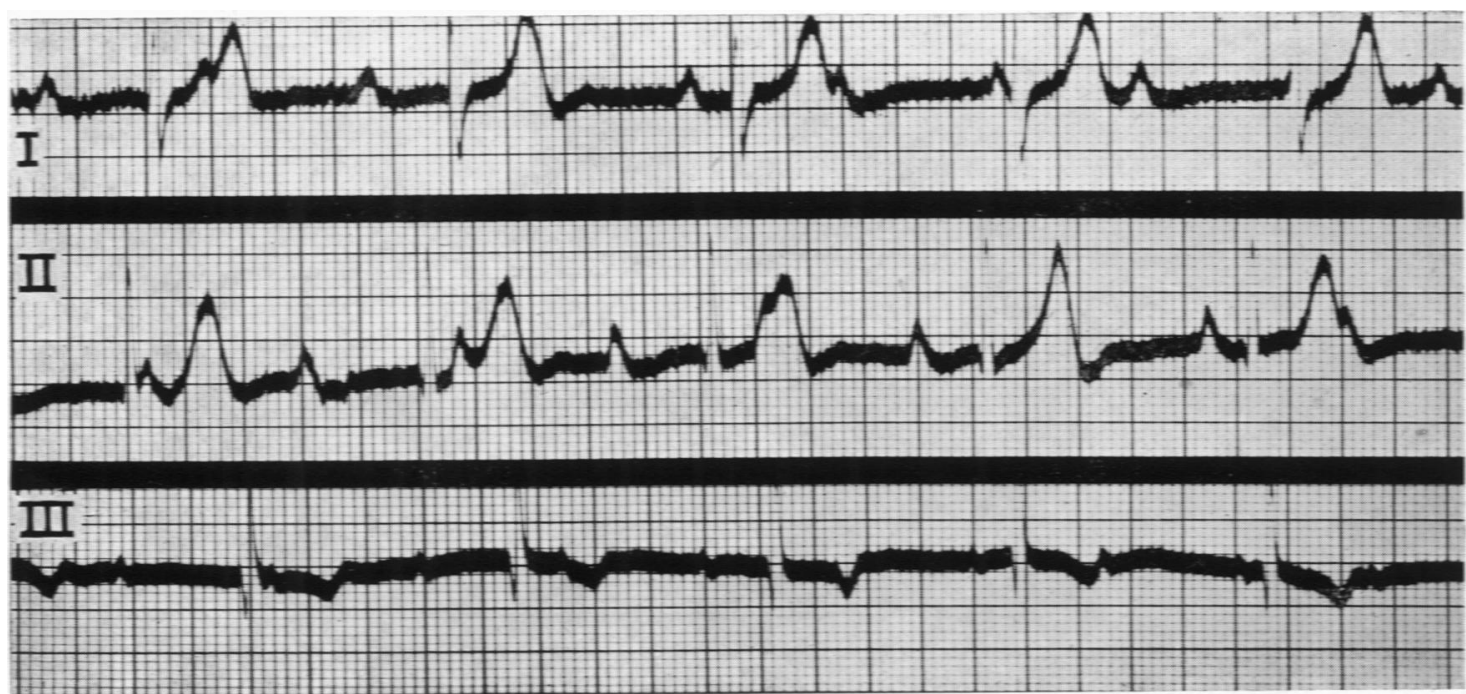

Fig. 5.-Case 3: electrocardiogram on March 26, 1947.

Plate II 
showed the heart to be globular and enlarged, probably more to the right than the left; screen examination confirmed slow, deep contractions and showed several flickering contractions on the right border between beats. An electrocardiogram (fig. 1) showed complete heart block with an auricular rate of approximately 124 and a ventricular rate of 30 ; right axis deviation was present. The Wassermann reaction was negative. Examination of the urine showed no abnormality. The red blood cell count was 5.6 million per c.mm. and the haemoglobin was 100 per cent. (Haldane).

During the next three weeks his condition showed no change except that the respiratory infection slowly cleared up. His pulse rate varied between 19 and 32, and in the first few days, when the bronchitis was fairly severe, was at times less than half the respiratory rate. Exercise and emotion had little effect on the heart rate, and hypodermic injections of atropine gr. $1 / 250$ and adrenaline $0.1 \mathrm{ml}$. produced no cardiac acceleration.

On Feb. 24 he had a Stokes-Adams attack, which corresponded closely to the description of the 'fits' which he had had at home. During the next week he had similar attacks every day, the number in twenty-four hours varying from two to ten. Excitement or fear sometimes seemed to precipitate an attack, but this was inconstant and no other precipitating factor was detected. The course of a typical attack which was followed from start to finish was as follows: he gave an irritable cry and fell down; respiration became very slow and stertorous and cyanosis developed rapidly; there was urinary and faecal incontinence; no ventricular sounds were heard for thirty seconds but there were occasional fluttering sounds during this period which might have been caused by auricular beats; during the next fifty seconds six faint ventricular beats were heard but no radial pulse was palpable; normal ventricular sounds then suddenly restarted and the pulse became palpable, the rate during the next minute being sixty; with the resumption of normal ventricular beats respiration became more regular and the cyanosis faded and was succeeded by pallor; during the earlier stages of the attack he had been generally rigid, and this passed off into a state of general flaccidity without any clonic stage; he appeared conscious but dazed within two minutes of the commencement of ventricular beats; the pulse rate settled to thirty within three minutes; he remained pale and dazed for about ten minutes and thereafter appeared fairly normal but was tired and listless for the rest of the day.

After a week of daily attacks a remission occurred and there were only two isolated attacks in the succeeding twelve days. During this period he had another fairly severe attack of bronchitis and upper respiratory infection which was not accompanied by cyanosis or any evidence of cardiac embarrassment. He was discharged on March 16, 1946, his pulse rate. except during the Stokes-Adams attacks, never having risen above thirty-six throughout his stay in hospital.
On September 18, 1946, he was again seen as an out patient. Since his discharge from hospital he had continued to have attacks, at first five or six times per week, but latterly only once in about ten days. His health otherwise had been excellent; he was bright mentally and played with the other children of the family without dyspnoea or distress. On examination no change was found in his condition since his discharge from hospital; his pulse rate was 24. During examination he had a StokesAdams attack.

He did not report again but his condition is said to have remained unchanged until he died at home during a Stokes-Adams attack on Feb. 7, 1947.

Case 2. A girl aged five years was admitted to this hospital on Feb. 1, 1947, with the history that for the previous six months she had been listless, easily tired, and slightly breathless on exertion. For one month she had complained of some pain in the sternal region and upper abdomen, usually at night.

Previous history. At the age of six months she was admitted to Aberdeen City Hospital on account of 'marasmus.' Apart from grossly infected tonsils (which were later removed) and bilateral suppurative otitis media no abnormality was found and she was discharged after six weeks. During this time her pulse rate ranged between 110 and 130 per minute except on one occasion when a rate of 96 was recorded. She was again treated in Aberdeen City Hospital for four weeks at the age of one year and three months for infected scabies. On this occasion her pulse rate varied between 80 and 96 . Apart from intermittent aural discharge and an attack of chicken pox, she had, thereafter, remained healthy until the onset of her present illness.

FAMILY HISTORY. The parents are healthy and are not consanguineous. There are five children older than the patient, all healthy, and one younger - Case 3. The parents and the five older children were examined and no cardiac abnormalities were found; all had normal electrocardiograms. The mother has had no other children, no miscarriages, and no stillbirths.

Physical examination. She was a pale listless child with severe nasal catarrh. Her temperature was $103^{\circ} \mathrm{F}$., pulse rate 100 , and respiratory rate 24 per minute. The apex beat of the heart was in the fourth left interspace just beyond the nipple; there were systolic and short early diastolic murmurs at the mitral area; the systolic murmur was soft and was conducted all over the precordium; the diastolic murmur was not conducted; the pulmonary second sound was normal. There were râles at both lung bases. Examination was otherwise negative. A diagnosis of rheumatic carditis and acute bronchitis was made.

On Feb. 2 she developed a typical measles rash and on the following day she was transferred to Aberdeen City Hospital. A course of penicillin was given, and on Feb. 4 her temperature fell to 
normal and remained so. Her pulse rate (see chart), which was 118 on Feb. 3, fell steadily to 90 on Feb. 6, rose again to 120 on the following morning, and remained above that level till the morning of Feb. 9. During that day she had no symptoms of any kind, but in the evening her pulse rate had fallen to 40; it remained between 40 and 60 until she was transferred back to this hospital on Feb. 18.

On examination on that date her general condition was found to have improved since her previous admission. The nasal catarrh and the râles in the lungs had cleared up. Her apex beat was now in the fifth interspace, one inch beyond the nipple line; the cardiac murmurs were unchanged. Her blood pressure was $120 / 90 \mathrm{~mm}$. $\mathrm{Hg}$, and her erythrocyte sedimentation rate was $18 \mathrm{~mm}$. in one hour (Westergren).

Her waking pulse rate varied between 70 and 100 , and her sleeping pulse rate between 50 and 80 per minute for the next two and a half weeks, after which the rates seldom exceeded 60 and 50 respectively.

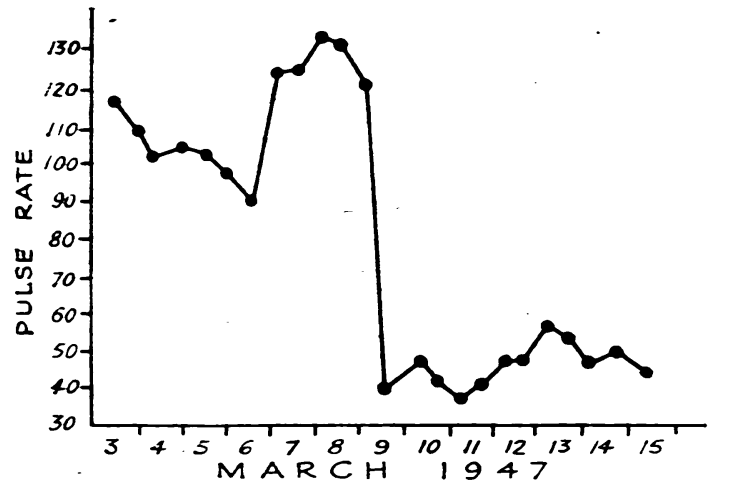

CHArt.-Case 2: pulse chart from the day following the appearance of the measles rash.

An electrocardiogram (fig. 2) on March 7 showed the presence of complete heart block with an auricular rate of 120 and a ventricular rate of 68 . A radiograph of the chest on March 10 (fig. 3) showed a moderate degree of cardiac enlargement, especially to the left.

Hypodermic injections of atropine gr. 1/150 and adrenaline $0.2 \mathrm{ml}$. produced no cardiac acceleration.

She was kept at rest in bed until May 2, and was then allowed a gradually increasing amount of activity and was finally discharged on June 18, 1947. During the whole of this period she had no symptoms referable to her cardiac condition and her cardiac murmurs remained unchanged.

She was seen again as an out patient on July 12 and Nov. 11, 1947. She had remained well during this period and is said to have been as active as before her illness. On examination on both occasions no change was found in the cardiac signs. Her pulse rate remained between 40 and 50 , and electrocardiograms confirmed the persistence of complete heart block.
Case 3. A boy aged three years, brother of Case 2, was admitted to this hospital on March 18, 1947. He had been admitted to Aberdeen City Hospital on Jan. 30, 1947, with acute bronchitis and upper respiratory infection. No cardiac abnormality was noted on admission. He was given a course of sulphamezathine and the bronchitis improved considerably. On Feb. 11, while still in the City Hospital, he developed a typical measles rash with a flare-up of the catarrhal signs in the nose and lungs. Prior to this date his pulse rate had varied between 72 and 92; thereafter, although no dramatic fall in pulse rate, such as occurred in Case 2, was observed, the pulse rate varied between 42 and 64 per minute. A radiograph on Feb. 18 was reported on as follows: "The heart shadow is enlarged but the right border is obscured by marked congestion of the right lung, especially towards the base. The left lung is also much congested. The right heart is probably enlarged.' An electrocardiogram on March 1 showed complete heart block with an auricular rate of 96 and a ventricular rate of 65 . The measles ran an otherwise uncomplicated course and he was discharged on March 2. He remained very listless, was at times breathless on exercise, and had a persistent cough until his admission to this hospital on March 18.

Previous history. He had twice been in Aberdeen City Hospital in infancy, once with bronchitis at the age of nine weeks, and once with gastro-enteritis three weeks later. He spent a total period of one month in hospital, and during this time his pulse rate was between 124 and 140 per minute. Thereafter he remained a healthy, active child.

Physical examination. His general condition was fair; his temperature was $102^{\circ} \mathrm{F}$., pulse rate 84, and respiratory rate 24 per minute. There was some nasal catarrh and a few scattered rhonchi over both lungs. The heart was not clinically enlarged; there were systolic and short middiastolic murmurs at the mitral area, both conducted for a short distance towards the mid-line. The blood pressure was $140 / 90 \mathrm{~mm}$. Hg. Examination was otherwise negative.

A radiograph of the chest (fig. 4) on March 20 showed accentuated broncho-vascular markings, especially in the basal areas; the transverse cardiac diameter was slightly above the average.

An electrocardiogram on March 26 (fig. 5). showed complete heart block with an auricular rate of 110 and a ventricular rate of 60 .

Hypodermic injection of adrenaline, $0.2 \mathrm{ml}$, produced no significant rise in pulse rate but there was an acceleration from 54 to 86 between thirty and fifty minutes after injection of atropine, gr. $1 / 150$.

The signs of respiratory infection cleared up a few days after admission; the temperature fell to normal within two days and the pulse rate fell to 60 within five days. Thereafter the waking pulse rate varied between 50 and 60 and the sleeping pulse rate. 
between 40 and 50 . The erythrocyte sedimentation rate was normal after the first week. The cardiac murmurs remained unchanged. He was kept at rest in bed until May 24 and was discharged on June 9 , by which time he was moderately active. At no time did he have any symptoms referable to his cardiac condition.

He was seen as an out patient on July 12 and Nov. 11, 1947. He is stated to have remained well and active during this period, apart from a severe attack of bronchitis for which he was admitted to Aberdeen City Hospital on Oct. 2; he remained in hospital for two weeks and his bronchitis cleared up satisfactorily. On examination on July 12 and Nov. 11 the cardiac signs were unchanged except for the development of a faint systolic murmur at the pulmonary area; the second sound at this area remained normal. Electrocardiograms at both examinations confirmed the persistence of complete heart block.

\section{Discussion}

Etiology. The finding of such an uncommon condition in childhood as complete heart block in a sister and brother, as in Cases 2 and 3, appears at first sight strong evidence that the condition in these cases is a familial defect. That there must have been some familial weakness in the conducting tissues of the heart appears almost certain, but this need not necessarily have been of such a degree as to produce complete heart block. The fact that both children during fairly prolonged periods in hospital in infancy had normal pulse rates is strong evidence against the heart block being congenital; cardiac rates in the region of 80 have been reported in complete block in infancy (Thomson, 1943) but, so far as I am aware, no case has been recorded with a rate over 100. Furthermore the pulse chart in Case 2 during her attack of measles can hardly be explained except on the basis of the block developing on the seventh day following the appearance of the rash; for the first four days the pulse rate fell steadily to an almost normal level; it then rose suddenly, without accompanying pyrexia, which suggests cardiac damage, and remained between 120 and 132 until the morning of the seventh day; by that evening it had dropped to 40 and it remained between 40 and 60 until the child returned to this hospital nine days later. The pulse rate in Case 3 showed no such dramatic fall, but from the day of the appearance of the measles rash it remained at a definitely lower level than previously.

Congenital heart block as a familial condition is extremely rare. Aitken (1932) quotes the case of two sisters with complete congenital heart block, originally reported by Aylward (1928), and states that this is the only authenticated example of familial block. Wallgren and Winblad (1937) subsequently reported three cases of heart block in one family. I can find no record of any other cases.

If it be accepted that the heart block in both these cases developed during the attacks of measles, then it seems certain that measles was at least a precipitating factor in the etiology.

The possibility that rheumatic carditis was also a factor in the production of the block cannot, however, be excluded in Cases 2 and 3, particularly the former, whose history prior to admission is consistent with an insidiously developing rheumatism. Case 3, however, has no such history and at the age of three is extremely young to have established rheumatic mitral disease such as would explain the murmurs heard. The possible significance of the cardiac murmurs in these two cases is further discussed under 'symptomatology.'

In Case 1 the evidence that the heart block was the result of measles is less conclusive, but the fact that the first Stokes-Adams attack occurred during the course of the measles is very suggestive of an association between the two conditions. No pulse records before the onset of measles are available in this case, but the pulse rate (80 to 112) during his admission to hospital following the first series of Stokes-Adams attacks suggests that the block at that time may have been intermittent or incomplete, which would make a diagnosis of congenital block less likely. If the block was not congenital then, presumably, it must have been due to measles, as the child had had no other illnesses.

References to cardiac lesions of any type in measles are very scanty. Griffiths and Mitchell (1941) state that 'endocarditis, pericarditis and myocarditis rarely develop.' According to Harries and Mitman (1943) the changes present in the heart are those associated with acute toxaemic conditions. It seems probable that, if the heart block in the present cases is the result of measles, it must have been caused either by an inflammatory process in the myocardium or by an ensuing fibrosis.

Symptomatology. Case 1 had no symptoms other than the Stokes-Adams attacks; between these attacks he was outwardly a normal child and appeared to find a cardiac rate of 20 to 30 per minute adequate for a fairly normal degree of activity. As already mentioned it is probable that the block was at first intermittent or incomplete, and the history gives no indication of the date of onset of complete and permanent block. While it is generally admitted that Stokes-Adams attacks are most likely to occur during the development of heart block, it is, as Parkinson et al. (1941) point out, a mistake to assume that, when the block becomes complete, the attacks always cease. The periodic nature of the attacks in this case remains unexplained. The attacks did not appear to be related to respiratory infection nor to any other obvious factor.

The extremely low diastolic pressure $(20 \mathrm{~mm}$.) in this boy can be explained adequately by the very slow cardiac rate with consequent prolonged period of diastole which would allow time for a considerable drop in pressure (Best and Taylor, 1943). There were no signs suggesting aortic incompetence. 
Cases 2 and 3 have remained free from any symptoms directly referable to the heart block. This in itself is perhaps not very surprising but it does seem remarkable that neither child showed any signs of distress during the period when the block was developing; this contrasts markedly with cases of diphtheria who develop heart block, all of whom are very ill and few of whom survive.

Of physical signs in Cases 2 and 3 , the most interesting and most difficult to explain are the systolic and diastolic murmurs at the mitral area, almost identical in both cases. The murmurs in site and character were indistinguishable from those heard in rheumatic mitral endocarditis and were not suggestive of any congenital lesion. In Case 2 there is a history consistent with insidiously developing rheumatic carditis, and the murmurs were certainly present before the signs of heart block appeared. It is, therefore, reasonable to argue that the original diagnosis of rheumatic carditis was correct and that it explains the cardiac murmurs. Case 3, however, is very young to have established mitral disease and has no history of any previous rheumatic manifestations. In his case the presence of the murmurs was not detected until the heart block was established, but it is possible that on his original admission to hospital with acute bronchitis the murmurs might have been obscured by the loud respiratory sounds.

The radiographs in these two cases are not inconsistent with the presence of mitral disease, and in Case 2 support is given to this diagnosis by the results of a barium swallow, which showed evidence of some enlargement of the left auricle.

Prognosis and management. In Case 1 the prognosis was considered poor in view of the frequency of the Stokes-Adams attacks, and this proginosis was subsequently proved correct by his death one year after first coming under observation. Alderson (1932) has reported the case of a boy, aged eleven years, with complete heart block who had had repeated Stokes-Adams attacks for three years and who remained in relatively good health though somewhat dyspnoeic on exercise. Repeated Stokes-Adams attacks are, therefore, evidently compatible with survival for some years, but it seems probable that they must in themselves damage the myocardium and materially worsen the prognosis.

The prognosis in Cases 2 and 3 is more difficult to assess. Whether the heart block is the result of localized disease in the neighbourhood of the conducting tissues or of more widespread myocarditis remains uncertain, and the possibility that both children may have rheumatic mitral disease is a further complicating factor. If the heart block is due to localized disease involving the conducting tissues, then the end result may fairly be compared to congenital block, a condition which, as Campbell (1943) has shown, is compatible not only with survival to at least early middle age but also with a comparatively active life. On the other hand, if the injury to the conducting tissues is part of a more widespread carditis, the prognosis will depend on the extent of the valvular and myocardial damage.

Both children were kept in bed for three months after the presumptive date of onset of the heart block and were thereafter allowed a gradually increasing amount of exercise. On their discharge from hospital the mother was advised not to attempt to restrict their activities provided no signs of distress appeared and the children remained otherwise healthy.

Three cases of complete heart block in young children are reported.

In each case it seems probable that the condition developed during an attack of measles.

One case had frequent Stokes-Adams attacks and died two years after the onset of heart block.

The other two cases, brother and sister, have had no symptoms directly referable to the heart block and are alive and well nine months after the block developed.

It is suggested that in all three cases the heart block is the result of measles, but the possibility that rheumatic carditis and some familial weakness of the conducting tissues may have played a part in the etiology of two of the cases is admitted.

I wish to express my gratitude to Professor John Craig and Dr. Ian Gordon for advice and encouragement in the preparation of this paper; to Dr. H. J. Rae for allowing me access to the records of Aberdeen City Hospital; to Dr. R. J. Duthie for the electrocardiograms; and to Dr. W. H. Milligan for the radiographs.

\section{REFERENCES}

Aitken, J. K. (1932). Lancet, 2, 1375.

Alderson, L. A. (1932). Amer. J. Dis. Child., 43, 514. Aylward, R. D. (1928). Brit. med. J., 1, 943.

Best, C. H., and Taylor, N. B. (1943). The Physiological Basis of Medical Practice. Baltimore: Williams and Wilkins Co. p. 206.

Bower, H. J. (1939). Lancet, 2, 686.

Campbell, M. (1943). Brit. Heart J., 5, 15.

Griffith, J. P. C., and Mitchell, A. C. (1941). Textbook of Pediatrics. Philadelphia: W. B. Saunders Co. p. 231.

Harries, E. H. R., and Mitman, M. (1943). Clinical Practice in Infectious Diseases. Edinburgh: E. and S. Livingstone. p. 206.

Leys, D. (1943). Brit. Heart J., 5, 8.

Logue, R. B., and Hanson, J. F. (1945). Amer. Heart J., 30, 205.

Parkinson, J., Papp, C., and Evans, W. (1941). Brit. Heart J., 3, 171.

Seham, M. (1925). 'Electrocardiograph in Congenital Heart Disease,' in Abt's Pediatrics. Philadelphia: W. B. Saunders Co., vol. 4, p. 333.

Thomson, J. (1943). Arch. Dis. Childh., 18, 190.

Wallgren, A., and Winblad, S. (1937). Acta paediatr., Stockh., 20, 175.

White, P. (1945). Heart Disease. New York: The Macmillan Co. p. 929. 